\title{
A Curious Case of Total Anomalous Pulmonary Venous Connection
}

\author{
Dr. Tanay Padgaonkar ${ }^{1}$, Dr. Kunal Bhuta ${ }^{2}$ \\ ${ }^{1}$ Senior Resident, Department of Cardiology, MGM Hospital and Medical College, Kamothe \\ ${ }^{2}$ PG Student, MGM Hospital and Medical College, Kamothe.
}

\begin{abstract}
First reported in the "Philosophical Transactions of Royal Society of London" in 1798, total anomalous pulmonary venous connection (TAPVC), also referred to as total anomalous pulmonary venous return (TAPVR), is a cyanotic congenital defect in which all four pulmonary veins fail to make their normal connection to the left atrium. This results in drainage of all pulmonary venous return into the systemic venous circulation. The incidence of total anomalous pulmonary venous connection (TAPVC) ranges from 0.6 to 1.2 per 10,000 live births ${ }^{[1,2]}$. Among patients born with congenital heart disease (CHD), the incidence of TAPVC ranges between 0.7 and 1.5 percent. It is the fifth most common cause of cyanotic CHD [1].75-90\% of symptomatic infants don't complete 1 year of life and most die in 3-6 months. Those who survive beyond 1 year of life almost always have a non-restrictive ASD. Exceptionally patient may reach even the 3rd-4th-5th decade of life with relatively little disability and a clinical picture that resembles Large ASD with mild cyanosis. Here,we review such an exceptional case of a patient diagnosed to have TAPVC at the age of 17 years.
\end{abstract}

Keywords: TAPVC, anomalous venous connections, cardiology, aneurysmal vertical vein.

\section{Case Report}

A 17 year old female patient presented to MGM hospital with complaints of mild dyspnea on exertion, NYHA grade II. The patient was asymptomatic and was able to perform daily activities. Blood investigations were within normal limits. Chest xray incidentally showed a homogeneous mass in the left lung. Echocardiography showed situssolitus, atrioventricular and ventriculoarterial concordance, normally related great arteries, a large non-restrictive atrial septal defect with a right-to-left shunt, and moderate pulmonary arterial hypertension. The right-sided pulmonary veins seemed to join a confluence, which drained into the vertical vein, but the left sided pulmonary venous anatomy was not clear. Also it showed a large saccular/ aneurysmal dilatation of the vertical vein.

The patient was subsequently taken up for cardiac catheterization, which confirmed the presence of supradiaphragmatic TAPVC. All 4 pulmonary veins were seen draining into the confluence, which in turn drained into the vertical vein. The vertical vein showed an aneurysmal dilatation measuring $6.4 \mathrm{~cm} \times 7.3 \mathrm{~cm}$. Also the presence of a large non-restrictive obligatory Atrial septal defect was confirmed.

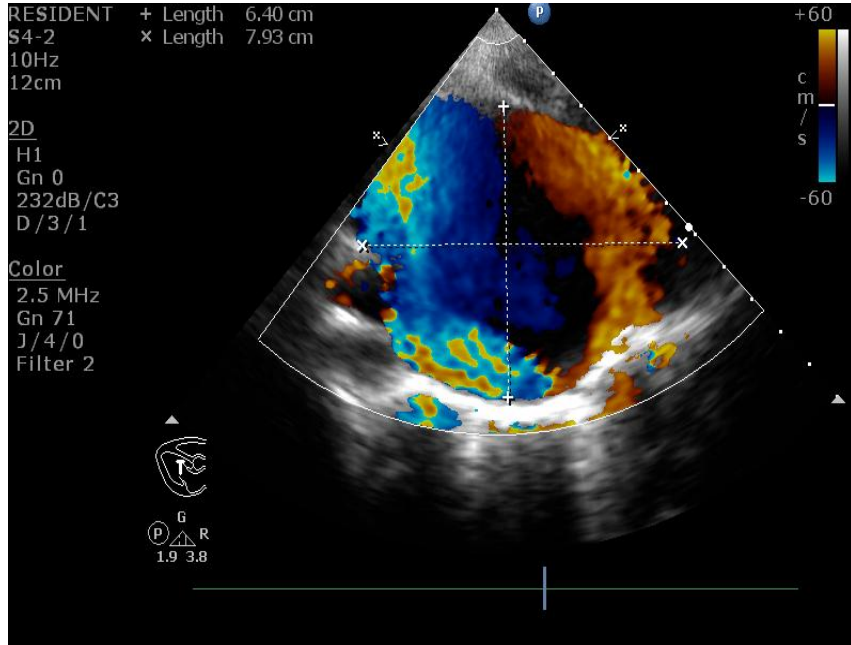

Aneurysmal Vertical Vein

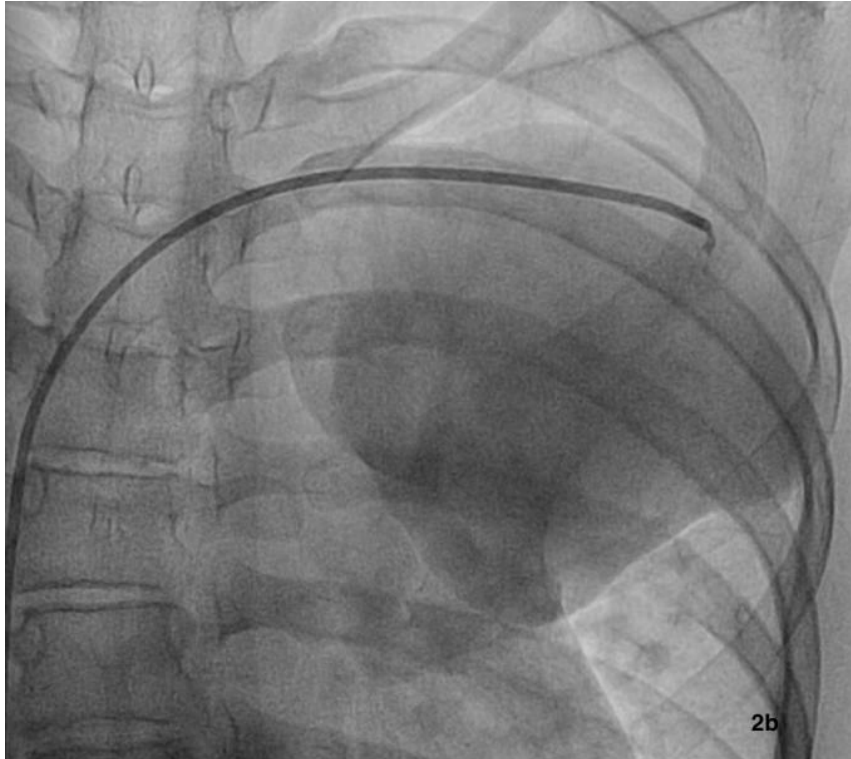

Dye injected into aneurysmal vertical vein 


\section{International Journal of Science and Research (IJSR) \\ ISSN (Online): 2319-7064}

Index Copernicus Value (2013): 6.14 | Impact Factor (2015): 6.391

\section{Discussion}

In normal development, the lung buds are formed from the primitive foregut and share a common vascular plexus (splanchnic plexus), which initially drains into the common cardinal and umbilicovitelline venous systems. With the formation of the lungs (27 to 29 days of gestation), a portion of the splanchnic plexus differentiates into the primitive pulmonary vascular bed ${ }^{[3]}$. During this same time period, the primitive left atrium forms a primordial evagination (common pulmonary vein) that grows into and joins the pulmonary portion of the splanchnic plexus. Once the connection is made, the primitive pulmonary venous system separates from the cardinal and umbilicovitelline veins. Portions of the common pulmonary vein are subsequently incorporated into the wall of the left atrium and become the two right and two left pulmonary veins, each of which enters the left atrium through a separate orifice.

In total anomalous pulmonary venous connection (TAPVC) there is failure of the left atrium to link to the pulmonary venous plexus, which results in the retention of connections to the primitive cardinal and umbilicovitelline drainage systems. The anatomic variants of TAPVC are dependent upon which connections are retained. The cardinal venous system provides connections to the innominate vein, right atrium, superior vena cava, or azygous vein, and the umbilicovitelline system to the portal or hepatic vein, or inferior vena cava.

The Classification takes in to account the pathway by which pulmonary venous blood reaches the RA, presence or absence of obstruction along the pathway and the nature of interatrial communication.Based on the pathway of venous blood it can be classified as Supracardiac (or Supradiaphragmatic), Infracardiac (or Subdiaphragmatic) and Mixed variety.

In the supracardiac variety, the pulmonary veins from both lungs course to a confluent chamber that is located just posterior to the left atrium. From this chamber, blood ascends through a vertically oriented vein that most often connects to the left innominate vein, which may further connect to the SVC. The other locations for connection of the left innominate vein include the right-sided superior vena cava, azygous vein, or a persistent left superior vena cava, which would drain to the right atrium via the coronary sinus.

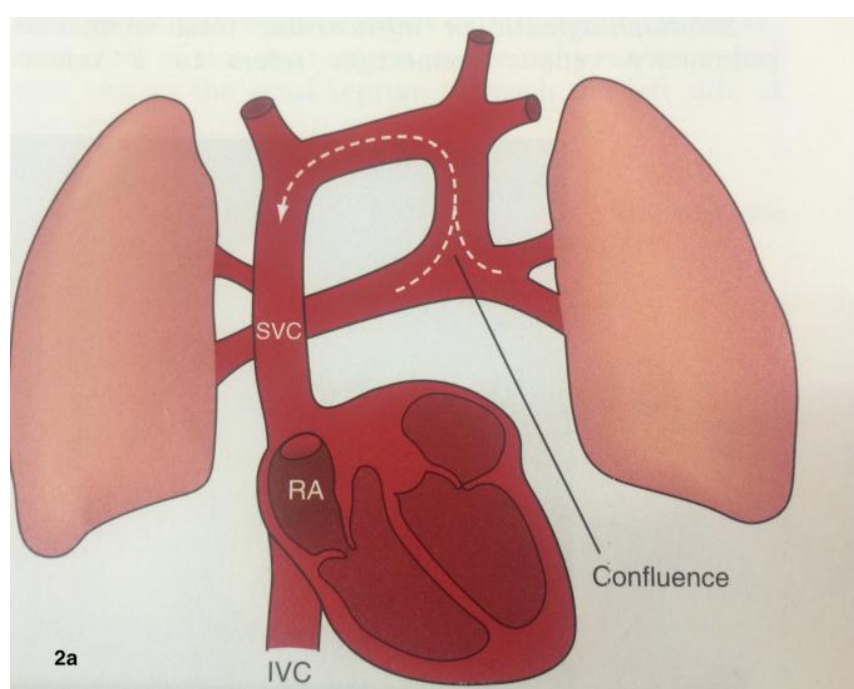

Sketch of Supradiaphragmatic TAPVC

Infracardiac TAPVC results from retained pulmonary vein connections to the umbilicovitelline venous system. This variety refers to a venous confluence from which vascular channel originates and descends anterior to the oesophagus, penetrates the oesophageal hiatus and terminates in the portal vein or less commonly in the IVC.

Mixed TAPVC refers to any combination of connections that enter at two or more different sites. The most common arrangement of mixed TAPVC is that of three pulmonary veins joining to form a single confluence and a fourth vein draining via a separate venous connection ${ }^{[4]}$.

The clinical manifestations vary and are dependent upon the presence and degree of pulmonary venous obstruction. In general, the more severe the obstruction, the earlier and more severe the presentation.Clinical features include Mild cyanosis with features of CHF. These patients often have a prominent precordium with left lower parasternal heave, loud S1 with a split S2 and loud P2. Ejection systolic murmur may be present in the pulmonary area due to increased pulmonary flow. Some patients may also have a pan systolic murmur due to tricuspid regurgitation and even a flow mid diastolic murmur at the tricusupid valve. Rarely a continuous murmur (resembling a venous hum) originating from the venous confluence and vertical vein may be heard maximally in the left upper sternal border.

ECG resembles an OS ASD ECG (RAD, RVH, incomplete $\mathrm{RBBB}$ ) when the Atrial septal defect is nonrestrictive. The $\mathrm{PR}$ interval is often prolonged and atrial fibrillation may be seen as with long standing OS-ASD patients. With development of Pulmonary artery hypertension, peaked $\mathrm{P}$ waves, tall right precordial $\mathrm{P}$ waves, deep left precordial $\mathrm{S}$ waves may be seen.

The diagnosis of total anomalous pulmonary venous connection (TAPVC) is generally made by echocardiography. TAPVC is one of three diagnoses that should be suspected in patients who present with cyanotic heart disease and respiratory symptoms due to pulmonary over circulation. Echocardiography can help identify the four pulmonary veins, the venous confluence and obstruction in the pulmonary venous pathways. 


\section{International Journal of Science and Research (IJSR) \\ ISSN (Online): 2319-7064 \\ Index Copernicus Value (2013): 6.14 | Impact Factor (2015): 6.391}

ColorDoppler can help identify the blood flow across the vertical vein, the innominate bridge and the SVC.In untreated patients, the natural course is dependent upon the presence and severity of obstruction, and the size of the interatrial communication. In general, the outcome is poor with a mortality rate of 80 percent by one year of age ${ }^{[5,6]}$.

In patients who present in the first few days of life with severe pulmonary obstruction usually die within the first month. Those with limited interatrial communication (restrictive atrial septal) have a mortality rate of about 80 percent in the first year of life. These patients develop severe heart failure, failure to thrive, and recurrent pulmonary infections.

The natural course of uncorrected patients with unobstructed total anomalous pulmonary venous connection (TAPVC) and sufficient interatrial communication varies. Some, like in our patient, may have only mild symptoms with exertion. However most eventually develop progressive right heart failure and pulmonary vascular disease due to pulmonary overcirculation.

Total anomalous pulmonary venous connection (TAPVC) requires surgical correction. The timing of surgery is dependent upon the degree of obstruction and the condition of the patient. Because the natural history of unoperated TAPVC is poor, surgical correction is recommended regardless of the degree of obstruction. In supra- and infracardiac TAPVC with a common vertical vein, a normal pulmonary venous pathway is created by opening and forming an anastomosis between the pulmonary venous confluence and the left atrium. The vertical vein is then ligated and divided. In infra-cardiac TAPVC that drains close to the right atrium, the interatrial septum is reconstructed to close the atrial septal opening and direct blood from the pulmonary veins directly to the left atrium.

With improved medical management (including extracorporeal membrane oxygenation [ECMO]), surgical techniques, and anesthesia, the survival rate has improved so that most patients with isolated total anomalous pulmonary venous connection (TAPVC) will survive ${ }^{[7,8]}$. Overall, longterm survival to adolescence is about 85 percent.

\section{References}

[1] Reller MD, Strickland MJ, Riehle-Colarusso T, et al. Prevalence of congenital heart defects in metropolitan Atlanta, 1998-2005. J Pediatr 2008; 153:807.

[2] Hoffman JI, Kaplan S. The incidence of congenital heart disease. J Am CollCardiol 2002; 39:1890.

[3] NEILL CA. Development of the pulmonary veins; with reference to the embryology of anomalies of pulmonary venous return. Pediatrics 1956; 18:880.

[4] Kirshborn P, Jaggers J, Underleider R. Total anomalous pulmonary venous connection. In: Pediatric Cardiac Surgery, 3rd ed, Mavroudis C (Ed), Mosby, Philadelphia 2003. p.612.

[5] BURROUGHS JT, EDWARDS JE. Total anomalous pulmonary venous connection.Am Heart J 1960; 59:913.

[6] Ward KE, Mullins CE. Anomalous pulmonary venous connections, pulmonary vein stenosis, and atresia of the common pulmonary vein. In: The Science and Practice of
Pediatric Cardiology, Garson A Jr, Bricker JT, Fisher DJ, Neish SR (Eds), Williams and Wilkins, Baltimore 1998. p.1431.

[7] Michielon G, Di Donato RM, Pasquini L, et al. Total anomalous pulmonary venous connection: long-term appraisal with evolving technical solutions. Eur J CardiothoracSurg 2002; 22:184.

[8] Hancock Friesen CL, Zurakowski D, Thiagarajan RR, et al. Total anomalous pulmonary venous connection: an analysis of current management strategies in a single institution. Ann ThoracSurg 2005; 79:596. 